\title{
Synthesis and Study of Properties of Organic and Carbon Xerogels from Abies Bark Tannins
}

\author{
Nadezhda M. Mikova*a , Ivan P. Ivanov ${ }^{a}$, \\ Vladimir A. Levdanskiy ${ }^{\mathbf{a}}$ and Boris N. Kuznetsov ${ }^{\mathbf{a}, \mathbf{b}}$ \\ ${ }^{a}$ Institute of Chemistry and Chemical Technology $S B R A S$ \\ $F R C$ «Krasnoyarsk Science Center SB RAS» \\ Krasnoyarsk, Russian Federation \\ ${ }^{b}$ Siberian Federal University \\ Krasnoyarsk, Russian Federation
}

Received 17.01.2020, received in revised form 20.02.2020, accepted 02.04.2020

Abstract. Methods of organic and carbon xerogels synthesis based on the use of condensed tannins isolated from abies bark were developed. Organic gels were synthesized by sol-gel condensation of tannins with formaldehyde in a solution of ethanol in the presence of catalysts $(\mathrm{NaOH}$ or $\mathrm{HCl})$. The final gelation products were dried by alternating low $\left(-18--40{ }^{\circ} \mathrm{C}\right)$ and room temperature to obtain tanninformaldehyde (TF) xerogels. FTIR study indicates that the formation of xerogels was accompanied by crosslinking reactions mainly due to the formation of carbon-carbon and alkyl ether bonds. Using the method of thermogravimetry, it was found that organic TF xerogels are thermally stable up to a temperature of $295^{\circ} \mathrm{C}$ and they are resistant to ignition in air at temperatures up to $600{ }^{\circ} \mathrm{C}$ and can be used as thermo- and fire-retardant materials.

Carbon tannin-formaldehyde xerogels were obtained by carbonization of organic xerogels at $800{ }^{\circ} \mathrm{C}$ in an argon atmosphere. The porous structure and surface morphology of organic and carbon xerogels was studied by BET- and SEM-methods. A significant development of the specific surface area (to $483-524 \mathrm{~m}^{2} / \mathrm{g}$ )as a result of the organic xerogels carbonization was established. Using SEM, it was shown that in carbon gels a spatially cross-linked structure of polymer chains consisting of 5-10 nmsized globule particles forming nanometer-sized pores is retained.

Keywords: tannins, abies bark, formaldehyde, sol-gel condensation, organic and carbon xerogels, structure, thermal properties.

(C) Siberian Federal University. All rights reserved

This work is licensed under a Creative Commons Attribution-NonCommercial 4.0 International License (CC BY-NC 4.0).

* Corresponding author E-mail address: nm@icct.ru 


\title{
Синтез и изучение свойств органических \\ и углеродных ксерогелей \\ из танинов коры пихты
}

\author{
Н.М. Микова ${ }^{a}$, И.П. Иванов \\ В.А. Левданский ${ }^{\mathrm{a}}$, Б.Н. Кузнецов ${ }^{\mathrm{a}, \boldsymbol{\sigma}}$ \\ ${ }^{a}$ Институт химии и химической технологии СО РАН \\ ФИЦ «Красноярский научный центр СО РАН» \\ Российская Федераиия, Красноярск \\ ${ }^{6}$ Сибирский федеральньй университет \\ Российская Федерачия, Красноярск
}

Аннотациия. Предложены методы синтеза органических и углеродных ксерогелей на основе конденсированных танинов, выделенных экстрагированием из коры пихты. Органические гели синтезировали методом золь-гель-конденсации танинов с формальдегидом в растворе этанола в присутствии катализаторов $(\mathrm{NaOH}$ или $\mathrm{HCl})$. Сушку конечных продуктов гелирования осуществляли чередованием пониженной (минус 18 - минус $40{ }^{\circ} \mathrm{C}$ ) и комнатной температур с получением танин-формальдегидных (ТФ) ксерогелей. ИК-спектроскопическое изучение свидетельствует о том, что процесс образования ксерогелей сопровождается реакциями сшивки преимущественно за счет образования углерод-углеродных и алкилэфирных связей. Методом термогравиметрии установлено, что органические танин-формальдегидные ксерогели термически стабильны вплоть до температуры $295{ }^{\circ} \mathrm{C}$, проявляют устойчивость к воспламенению на воздухе при температурах до $600{ }^{\circ} \mathrm{C}$ и могут найти применение в качестве термо- и огнезащитных материалов.

Углеродные танин-формальдегидные ксерогели были получены карбонизацией органических ксерогелей при $800{ }^{\circ} \mathrm{C}$ в атмосфере аргона. Пористая структура и морфология поверхности органических и углеродных ксерогелей были изучены методами БЭТ и сканирующей электронной микроскопии (СЭМ). Установлено значительное (до 483 - 524 м²/г) развитие удельной поверхности в результате карбонизации органических ксерогелей. Методом СЭМ показано, что в углеродных гелях сохраняется пространственно сшитая структура из полимерных цепочек, состоящих из глобулярных частиц размером 5-10 нм, образующих поры нанометрового размера.

Ключевые слова: танины, кора пихты, формальдегид, золь-гель-конденсация, органические и углеродные ксерогели, строение, термические свойства. 
Цитирование: Микова, Н.М. Синтез и изучение свойств органических и углеродных ксерогелей из танинов коры пихты / Н.М. Микова, И.П. Иванов, В.А. Левданский, Б.Н. Кузнецов // Журн. Сиб. федер. ун-та. Химия, 2020. 13(2). C. $175-188$. DOI: $10.17516 / 1998-2836-0173$

В последние годы возрос интерес к синтезу и применению полимерных органических и углеродных гелей, которые представляют собой пористые структурированные системы с трехмерной сетчатой структурой, образованной частицами преимущественно нанометрового размера [1-3]. Такие особенности органических и углеродных гелей, как химическая стабильность, термическая устойчивость, высокая пористость, разновидность форм (блоки, порошки, гранулы, пленки и др.), открывают перспективы их использования в катализе [4], адсорбции [5], электрохимии [6], в качестве конденсаторов топливных элементов [7, 8], теплоизоляторов [9] и в других областях.

Органические гели, как правило, синтезируют золь-гелевой поликонденсацией альдегидов, чаще формальдегида, с синтетическими фенольными соединениями, такими как резорцинол или фенол [10-12]. В зависимости от применяемого способа сушки на конечной стадии их синтеза гели могут быть выделены в виде аэрогелей, ксерогелей или криогелей $[2,13,14]$. При этом материалы, имеющие развитую пористость, обычно получают с применением на конечной стадии синтеза суперкритических условий их сушки в среде $\mathrm{CO}_{2}$ (аэрогели) $[1,3]$ или вымораживания в вакууме после стабилизации трет-бутиловым спиртом (криогели) [6]. Традиционный способ высушивания, т.е. докритическая сушка при атмосферных условиях на воздухе, при нагревании или в вакууме, приводит к образованию ксерогелей [10], которые имеют, как правило, большую плотность и меньший объем пор, чем аэрогели или криогели.

Важная задача - совершенствование методов синтеза органических гелей путем подбора нетоксичных, недорогих реагентов и оптимальных условий процесса. В последнее время интенсивно развиваемой областью исследований является синтез органических и углеродных гелей на основе натуральных биополимеров (целлюлозы, лигнинов, танинов, их смесей и др.). Природные биополимеры перспективны для использования в синтезе новых углеродных материалов благодаря их доступности, возобновляемому характеру, низкой стоимости и экологической безопасности.

Высокая реакционная способность конденсированных танинов обусловлена наличием в них большого количества гидроксильных групп [15]. Для приготовления органических и углеродных гелей широко используют танины, выделенные преимущественно из древесины и коры тропических разновидностей мимозы и акации (квебрахо) [16, 17].

Структуры конденсированных танинов (полифлаваноидов), выделенных из различного вида сырья, различаются по содержанию гидроксильных групп в мономерных звеньях, по соотношению цис- и транс-мономеров катехина и эпикатехина, а также по степени полимеризации $[15,18]$. Несмотря на специфические различия в структуре и составе флавоноидных единиц, конденсированные танины квебрахо, коры пихты и ели являются типичными представителями фенольных веществ пирокатехиновой группы [19], имеющими близкую реакционную способность по отношению к формальдегиду в реакции синтеза органических гелей.

Литературный анализ показывает, что использование танинов позволяет получать органические ксерогели с регулируемой пористостью путем подбора соответствующих условий их синтеза $[16,17,20,21]$. 
Органические аэрогели можно преобразовать в пористый углеродный материал путем контролируемой термообработки (карбонизации) в инертной среде при температурах 600$1000{ }^{\circ} \mathrm{C}$. В процессе карбонизации удаляется кислород и протекают реакции ароматизации и конденсации, приводящие к образованию наноструктурированного углеродного материала $[22,23]$. Карбонизация способствует развитию площади поверхности геля за счет создания мезо- и микропористости ( $<2$ нм) в результате удаления летучих веществ при термообработке. Гели в углеродной форме термически и химически устойчивы, имеют высокую площадь поверхности, благодаря чему они перспективны в применении во многих областях $[4,5,24,25]$.

В настоящей работе показана возможность замены танинов квебрахо на более доступные конденсированные танины из коры пихты в синтезе танин-формальдегидных органических и углеродных полимерных гелей. При синтезе гелей использовали дешевый способ сушки при нормальных условиях вместо дорогих методов суперкритической и криогенной сушки. Целью работы являлось изучение состава и физико-химических свойств органических и углеродных полимерных танин-формальдегидных ксерогелей, синтезированных на основе конденсированных танинов пихты.

\section{Экспериментальная часть}

Приготовление органических танин-формальдегидных гелей проводили в соответствии с общепринятым методом [26]. Танины были извлечены из коры пихты этанолом после ее предварительного обессмоливания диэтиловым эфиром. Состав, \% мас.: С - 57,72; Н - 5,84; зола 0,4 . Средневесовая молекулярная масса (Mw) составляла 1884 г/моль.

Синтез ТФ-ксерогелей осуществляли в этаноле, в котором растворяли полифенольные вещества до требуемой концентрации, смешивали их с 37\%-ным водным раствором формальдегида при массовом соотношении 1,0:1,5. С целью регулирования $\mathrm{pH}$ реакционной среды в раствор добавляли $\mathrm{NaOH}$ или $\mathrm{HCl}$. Растворы, помещенные в герметично закрытые стеклянные пробирки, выдерживали в вентилируемом шкафу при температуре $75^{\circ} \mathrm{C}$ в течение 5 сут. Затем образовавшиеся гели извлекали из пробирок и помещали в колбу с этанолом, которую аккуратно встряхивали с помощью орбитального шейкера при температуре $40{ }^{\circ} \mathrm{C}$ в течение 3 сут. Для удаления побочных продуктов из пор геля этанол заменяли ежедневно.

Полученные образцы гелей после выдерживания при комнатной температуре в течение 6 ч замораживали при температуре минус $18-20^{\circ} \mathrm{C}$ в течение 48 ч при обычных условиях окружающей среды (воздух, атмосферное давление). После этого их переносили в камеру аппарата лиофильной сушки «Иней-6», где в процессе сублимационного вакуумного вымораживания происходила сушка при рабочем давлении 3,3 Па и температуре минус $44{ }^{\circ} \mathrm{C}$.

Карбонизацию органических предшественников осуществляли в продуваемой аргоном трубчатой электрической печи «Варта» с терморегулятором-измерителем программируемого типа ТП 703. Температура карбонизации $800{ }^{\circ} \mathrm{C}$, изотермическая выдержка 2 ч. Скорость нагрева печи $5{ }^{\circ} \mathrm{C} /$ мин, скорость потока газа аргона 500 мл/ч.

Выход карбонизатов (\% отн.) определяли на сухую массу исходного образца, ошибки определения выхода находились в пределах $\pm 1-3 \%$.

Текстурные характеристики органических и углеродных гелей измеряли методом равновесной адсорбции-десорбции азота при минус $196{ }^{\circ} \mathrm{C}$ в диапазоне относительных давлений 
P/Ро от 0.005 до 0.995 на автоматическом анализаторе ASAP 2020 (Micromeritics, США). Образцы органических ксерогелей тренировали в течение 2 ч при температуре $80{ }^{\circ} \mathrm{C}$, а образцы углеродных ксерогелей дегазировали в течение 2 ч в вакууме при $250{ }^{\circ} \mathrm{C}$ перед измерениями адсорбции. Для характеристики пористой структуры образцов использовали следующие параметры: удельную площадь поверхности, $\mathrm{S}_{\text {БЕт, }}$ определенную методом Брунауэра-Эммет-Теллеpa, и Vtot $\left(\mathrm{cm}^{3} / \Gamma\right)$ - суммарный объем пор, рассчитанный по объему сорбированного азота при относительном давлении $\mathrm{P} / \mathrm{Po} \geq 0.995$.

Распределение мезопор по размерам определяли методом Barrett-Joyner-Halenda (BJH) с использованием программного обеспечения, поставляемого с адсорбционным аппаратом ASAP 2020. Расчет объема микропор, Vmicro, произведен с помощью t-метода, а размер микропор получен из анализа функционала плотности (DFT-метод).

Термогравиметрическое изучение образцов органических гелей выполняли с использованием анализатора «Netzsch STA 449F1». Навеску образца нагревали в атмосфере аргона в алюминиевом тигле от 400 до $800{ }^{\circ} \mathrm{C}$ при скорости нагрева $10{ }^{\circ} \mathrm{C} /$ мин.

Элементный состав исследуемых образцов определяли с помощью анализатора HCNS-0 EA 1112 (Flash, США).

Регистрацию FTIR-спектров поглощения образцов в области 400-4000 см-1 осуществляли на ИК-Фурье-спектрометре Tensor 27 (Brucker, Германия) Красноярского центра коллективного пользования в матрице бромистого калия (5 мг/1000 мг матрицы). Обработку спектральной информации проводили с применением пакета программ OPUS, версия 5.0.

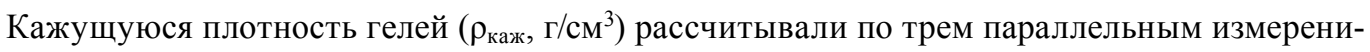
ям исходя из отношения веса измельченного образца к занимаемому им объему.

Микроструктуру образцов изучали методом сканирующей электронной микроскопии во вторичных (S5500, Hitachi) и в обратно отраженных электронах (TM-3000, Hitachi). Для снятия заряда и экранирования падающего пучка образцы предварительно подвергались напылению платиной (толщина напыления 10 нм) с помощью магнетрона K575X (Emitech, Англия).

\section{Результаты и их обсуждение}

Синтез и изучение свойств органических

танин-формальдегидных ксерогелей

Впервые предложено использовать в качестве альтернативы танинам квербахо, применяемым для получения полимерных гелей, новый источник полифенольных соединений пирокатехинового ряда - танины коры пихты.

Известно, что широко используемые для синтеза органических аэрогелей танины квебрахо содержат в своем составе от 80 до $82 \%$ фенольных флаваноидов [15, 16, 22]. Проведенными исследованиями установлено, что концентрация флаваноидных соединений в дубильных экстрактах пихты достигает 92-95 \%, а содержание сопутствующих органических и минеральных примесей, растворимых этанолом, минимально. Подтверждением высокого содержания полифлаваноидов является их практически полное превращение в антоцианидины в ходе известной реакции при нагревании их спиртовых растворов в кислой среде [19].

$$
-179-
$$




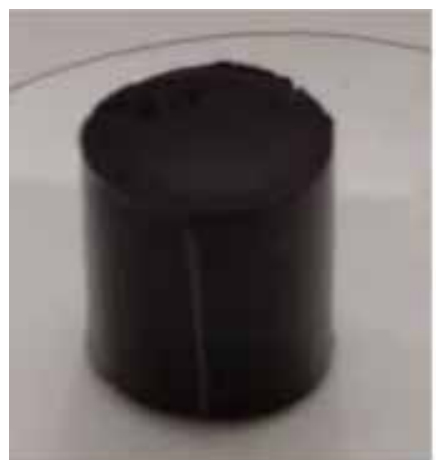

a

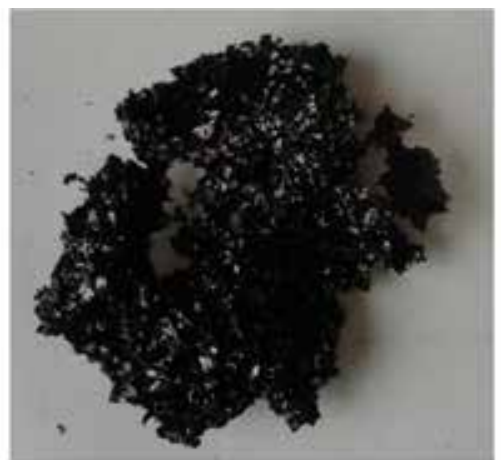

6

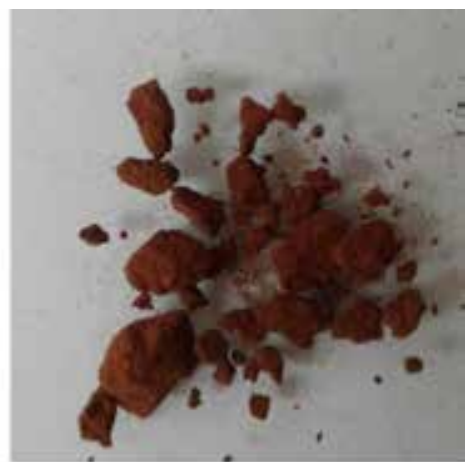

B

Рис. 1. Фотографии образцов органических ТФ-ксерогелей, полученных в присутствии $\mathrm{HCl}(\mathrm{a}$, б) и в среде $\mathrm{NaOH}($ в)

Fig. 1. Photographs of samples of organic TF xerogels obtained in the presence of $\mathrm{HCl}(\mathrm{a}$, б) and $\mathrm{NaOH}(\mathrm{B})$

Танин-формальдегидные гели были синтезированы в кислой и щелочной средах. На рис. 1 представлены фотографии ТФ-гелей, полученных путем регулирования рН добавлением растворов $\mathrm{HCl}$ или $\mathrm{NaOH}$.

Танин-формальдегидные гели, приготовленные в кислой среде, ТФ(НCl), представляют собой достаточно твердые, плотные продукты темно-коричневого цвета, которые хорошо сохраняли форму в виде блоков при извлечении и на стадии очистки геля (рис. 1a). Однако при окончательном высушивании в вакууме они становились хрупкими и распадались на более мелкие фрагменты (рис. 1б). Органический ТФ( $\mathrm{NaOH})$-ксерогель после сушки представляет собой более рыхлый комковатый продукт кирпично-красного цвета (рис. 1в).

Известно, что возникающие при сушке капиллярные силы создают большие внутренние напряжения в материале, что приводит к его усадке, сжатию и способствует его разрушению $[14,27,28]$. Замена широко используемого сверхкритического способа сушки на более дешевый, осуществляемый в обычных условиях, приводит к повышению плотности и снижению пористости в органических гелях.

Хотя замена такой стадии сверхкритической сушки на простую, докритическую является более доступной, все же во избежание значительной потери пористости в некоторых случаях допустимо использовать дополнительно вещества - суфрактанты, снижающие капиллярные натяжения в порах $[16,28]$.

Кажущаяся (насыпная) плотность полученных ксерогелей, рассчитанная исходя из отношения веса измельченного образца к занимаемому им объему, составила $0,24-0,67$ г/см ${ }^{3}$. Эти значения близки к значениям, типичным для большинства органических аэрогелей на основе

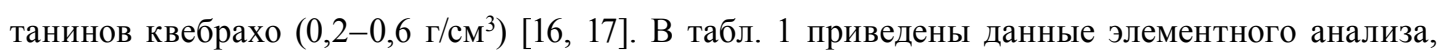
удельной поверхности ( $\mathrm{S}_{\text {Бэт }}$ ), объема пор (Уобщ.) и значения кажущейся плотности органических гелей, полученных при различных $\mathrm{pH}$.

Повышение значения $\mathrm{pH}$ среды при добавлении в реакционную смесь $\mathrm{NaOH}$ в некоторой степени способствует лучшему развитию пористости органических ТФ-ксерогелей из пихты. Однако при этом формируется механически непрочный гель. 
Таблица 1. Элементный состав (\% мас.) и характеристика пористости органических танинформальдегидных ксерогелей

Table 1. Elemental composition ( $\% \mathrm{wt}$ ) and porosity characteristics of organic tannin-formaldehyde xerogels

\begin{tabular}{|c|c|c|c|c|c|}
\hline Образец геля & $\mathrm{C}, \%$ & $\mathrm{H}, \%$ & $\mathrm{~S}_{\text {БЭТ }}, \mathrm{M}^{2} / \Gamma$ & Vобщ., $\mathrm{cm}^{3} / \Gamma$ & $\left(\mathrm{r}_{\text {каж}}, \Gamma / \mathrm{cm}^{3}\right)$ \\
\hline $\mathrm{T} \Phi(\mathrm{HCl})$ & 60,94 & 5,12 & 9,5 & 0.035 & 0,67 \\
\hline $\mathrm{T} \Phi(\mathrm{NaOH})$ & 60,30 & 5,74 & 11,4 & 0,046 & 0,24 \\
\hline
\end{tabular}

Пористая структура ксерогелей, полученных на основе конденсированных танинов пихты, была изучена методом низкотемпературной адсорбции-десорбции азота в диапазоне относительных давлений Р/Ро от 0.005 до 0.995. На рис. 2 представлены изотермы адсорбции-десорбции азота на органических ТФ-ксерогелях, синтезированных в условиях кислой и щелочной сред. Как следует из формы изотерм, они относятся преимущественно к IV типу, характерному для мезопористых материалов [29].

Результаты изучения пористой структуры показали, что в общем объеме пор образца органического ТФ(NaOH)-ксерогеля (рис. 2б) микропористый объем не превышает $10 \%$, а средний размер микропор $\leq 1,7$ нм. Объем мезопор, определенный методом Barrett-Joyner-Halenda (BJHметод), со средним размером пор 16,3 нм составляет около 76,3 \%.

Для ТФ( $\mathrm{HCl})$-ксерогеля (рис. $2 a$ ) отмечается снижение как общего пористого объема в 1,3 раза, так и объема микропор (4 \%). Образец отличается более широким распределением пор, присутствующих в интервале от 1,5 до 50 нм. При этом относительный вклад объема мезопор со средним размером пор 19,6 нм составляет 64,8 \%. Макропоры также присутствуют в структуре ксерогелей.

Подобное влияние $\mathrm{pH}$ среды отмечено в работе [30], где резорцин-формальдегидные аэрогели, полученные с использованием катализаторов основного типа ( $\left.\mathrm{NaOH}, \mathrm{Na}_{2} \mathrm{CO}_{3}\right)$, имели узкое распределение пор по размерам (между 10 и 20 нм), в то время как поры гелей, синтезиро-

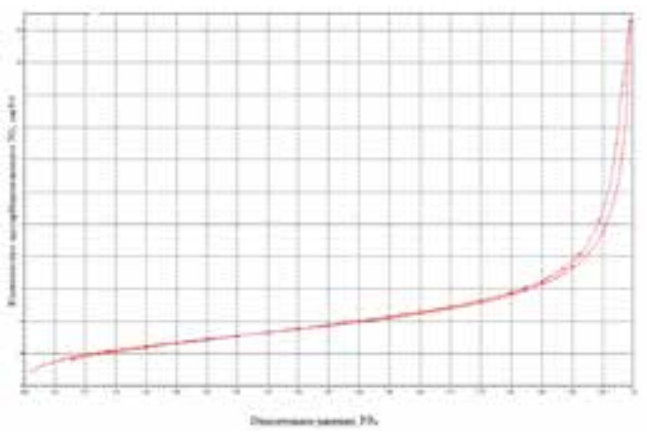

a) $\mathrm{T} \Phi(\mathrm{HCl})$

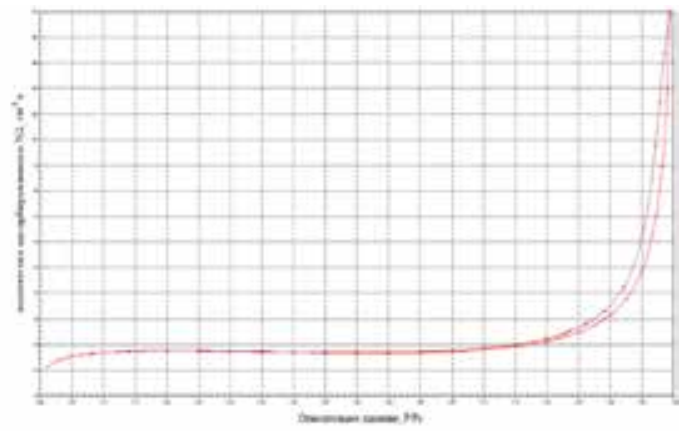

б) $\mathrm{T} \Phi(\mathrm{NaOH})$

Рис. 2. Изотермы сорбции-десорбции азота на образцах органических ТФ-ксерогелей, полученных в присутствии $\mathrm{HCl}$ (а) и $\mathrm{NaOH}(б)$

Fig. 2. Nitrogen sorption-desorption isotherms on samples of organic TF xerogels obtained in the presence of (a) $\mathrm{HCl}$ and (б) $\mathrm{NaOH}$ 
ванных в присутствии кислоты $(\mathrm{HCl})$, имели значительно большие размеры и более широкий диапазон их распределения по размерам.

Известно, что как щелочные, так и кислотные условия способствуют протеканию реакции золь-гель-конденсации танинов с альдегидами [31]. Разница состоит в том, что в кислой среде реакции между танинами и формальдегидом обусловлены протонированным формальдегидом, в то время как при высоких значениях рН нуклеофильность фенольных колец танинов увеличивается за счет образования высоко реакционноспособных фенолятов [32].

Микроструктура образцов танин-формальдегидных органических гелей, изученная методом сканирующей электронной микроскопии (СЭМ), представлена на рис. 3. СЭМ-снимки ТФксерогелей демонстрируют непрерывную протяженную целлюлярную структуру из однородных частиц. Разветвленные в различных направлениях полимерные продукты сформированы цепочками тесно связанных узелковых образований из частиц (кластеров) размером менее 0,2 мкм. Закрученные полимерные цепочки образуют полости от 0,2 до 0,5 мкм. Увеличение изображения в 60000 раз (рис. $3 a$ ) позволяет сделать заключение, что узелковые образования представляют собой скрученные в клубки ансамбли из частиц нанометрового размера.

Изучение морфологии полученных ТФ( $\mathrm{HCl})$ и ТФ( $\mathrm{NaOH})$-ксерогелей методом СЭМ подтвердило наличие узловой структуры из тесно связанных глобулярных частиц, обычно наблюдаемой для большинства описанных в литературе органических аэрогелей, в том числе полученных на основе широко используемых танинов квебрахо [6, 16, 33].

Как и в случае других подобных гелей, процесс конденсации танинов пихты с формальдегидом приводит к формированию трехмерно сшитого каркаса, сформированного узелками (микро- или наночастиц), за счет образования мостиковых связей. Подтверждение образования внутримолекулярных $-\mathrm{CH}_{2}-\mathrm{u}-\mathrm{CH}_{2}-\mathrm{O}-\mathrm{CH}_{2}-$ связей при взаимодействии формальдегида с фенольными и спиртовыми ОН-группами танинов пихты [22, 27], которые сшивают ароматические звенья в процессе поликонденсации, было получено из сопоставления ИК-спектров

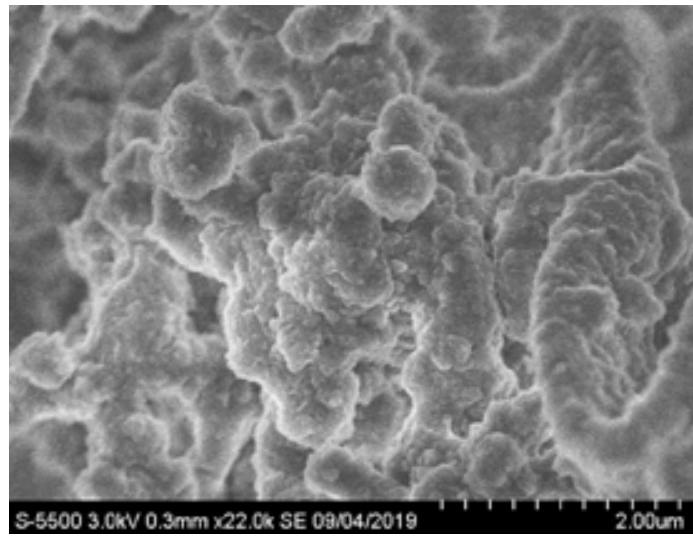

a) ТФ(NaOH) органический ксерогель

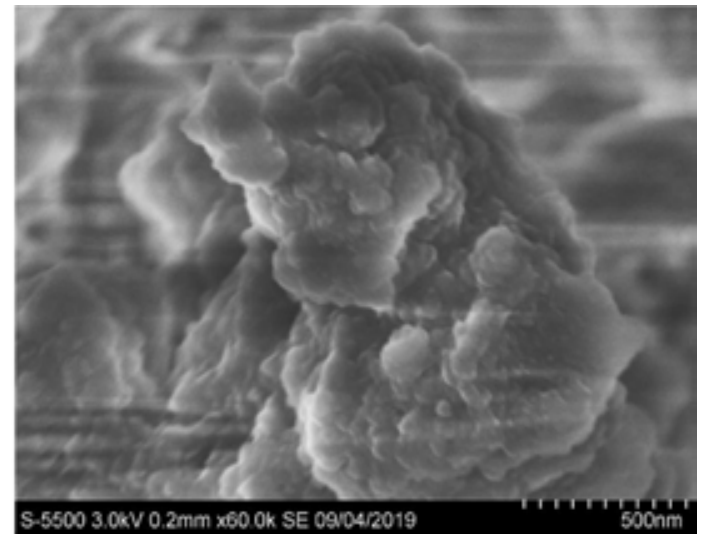

б) ТФ(HCl) органический ксерогель

Рис. 3. СЭМ-изображения образцов органических танин-формальдегидных ксерогелей: a - ТФ(HCl), увеличение $2,2 \times 10^{4}$ раз; б - ТФ(NaOH), увеличение $6 \times 10^{4}$ раз

Fig. 3. SEM-images of samples of organic tannin-formaldehyde xerogels: a - TF( $\mathrm{NaOH})$, magnification $2.2 \times 10^{4}$ times; $\sigma-\mathrm{TF}(\mathrm{HCl})$, magnification $6 \times 10^{4}$ times 


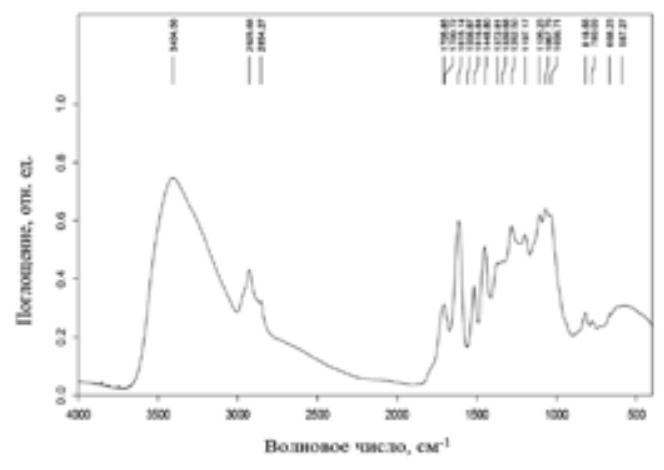

a

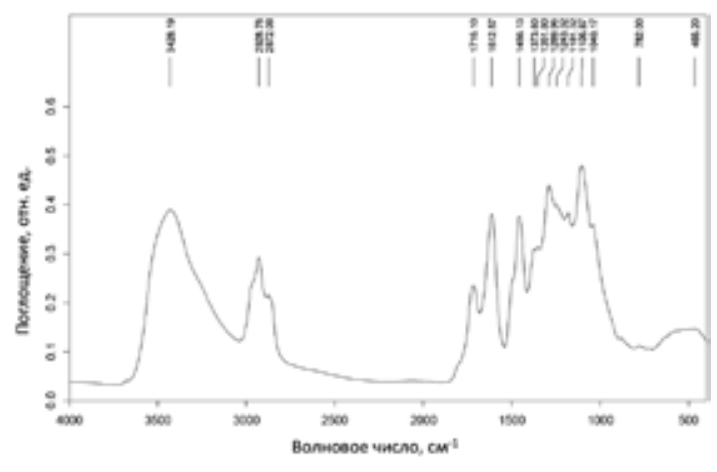

6

Рис. 4. ИК-спектры образцов танинов коры пихты (а) и полученного на их основе танин-формальдегидного органического ксерогеля ТФ(HCl) (б)

Fig. 4. IR spectra of samples of abies bark tannins (a) and $\mathrm{TF}(\mathrm{HCl})$ tannin-formaldehyde organic xerogel obtained on their basis (б)

танинов коры пихты и синтезированного на их основе танин-формальдегидного органического ксерогеля ТФ (HCl) (рис. 4).

Сравнительный анализ ИК-спектров этих образцов показал, что для ТФ-ксерогеля интенсивности полос поглощения (п.п.) при 2929 и $2872 \mathrm{~cm}^{-1}$, которые соответствуют валентным колебаниям С-Н в метильных и метиленовых группах, выше, чем для образца танинов [28]. Отсутствие в спектре ТФ-геля п.П. в области $876-780 \mathrm{~cm}^{-1}$, характерных для внеплоскостных деформационных колебаний $\mathrm{C}-\mathrm{H}-$ связей в 1,3-замещенных ароматических кольцах танинов, может указывать на изменение степени и характера их замещения по сравнению с исходными танинами. По мнению авторов [22], отсутствие п.П. в области 700-900 см-1 может свидетельствовать об увеличении степени замещения ароматических колец вследствие протекания реакций сшивки с формальдегидом.

\section{Изучение структуры и свойств углеродных}

танин-формальдегидных ксерогелей

Процесс карбонизации органических ксерогелей сопровождается изменением не только их состава (содержание углерода возрастает до 95-97 \%), но и пористой структуры. Изменения, происходящие в результате трансформации органического ксерогеля в углеродный, рассмотрены на примере образца ТФ( $\mathrm{HCl})$-ксерогеля. Как следует из формы и вида изотермы адсорбции $\mathrm{N}_{2}$ на образце ТФ углеродного ксерогеля (рис. 5), она отвечает комбинации I и IV типов, описывающей мезо-микропористое вещество [29].

На основании анализа изотермы с применением различных методов расчета получены сведения о пористой структуре углеродных ТФ-гелей. В процессе карбонизации значительно (до 50 раз) возрастает удельная поверхность образцов, значения которой достигают величины $483 \mathrm{~m}^{2} /$ г для ТФ $(\mathrm{HCl})$ и $524 \mathrm{~m}^{2} / \Gamma$ - для ТФ $(\mathrm{NaOH})$.

В общем пористом объеме ТФ( $\mathrm{HCl})$ углеродного ксерогеля доля объема микропор со средней шириной пор 1,94 нм составляет около 83 \%. Как следует из полученных данных, в результате карбонизации органического ТФ( $\mathrm{HCl})$-ксерогеля получается преимущественно 


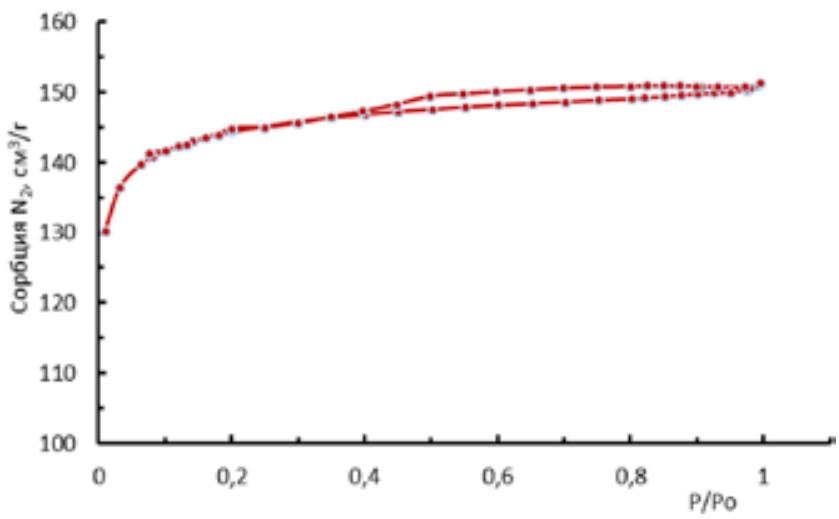

Рис. 5. Изотерма адсорбции-десорбции $\mathrm{N}_{2}$ на образце углеродного танин-формальдегидного геля

Fig. 5. $\mathrm{N}_{2}$ adsorption-desorption isotherm on carbon tannin-formaldehyde gel

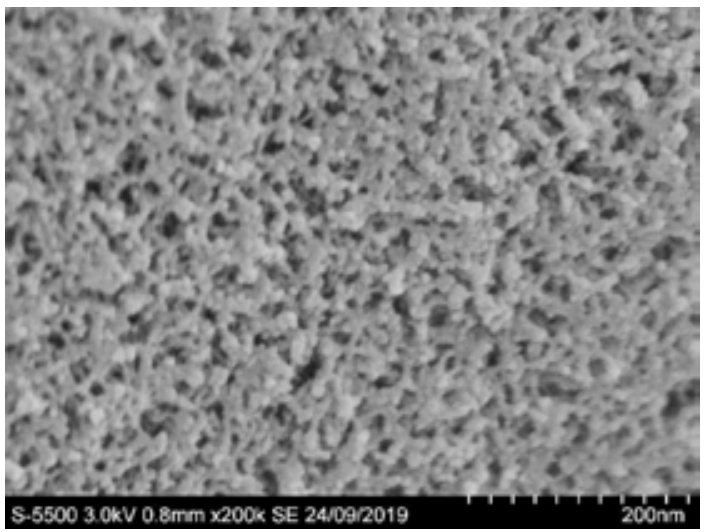

Рис. 6. СЭМ-изображение образца углеродного танин-формальдегидного геля (увеличение $2 \times 10^{5}$ раз)

Fig. 6. SEM-image of sample of carbon tannin-formaldehyde gel (magnification $2 \times 10^{5}$ times)

микропористый материал [34]. О подобном развитии микропористости в полимерных танинсодержащих углеродных гелях сообщалось в работах $[6,16,35]$.

Микропористую структуру углеродного ТФ( $\mathrm{HCl})$-ксерогеля демонстрирует СЭМ-снимок образца, снятого во вторичных электронах при увеличении в 200000 раз. Морфология поверхности, представленная на рис. 6, отражает заметные изменения, которые происходят в структуре геля в процессе карбонизации.

Открытые поры размером 10-20 нм образуются за счет высвобождения летучих органических соединений в процессе карбонизации. На снимке можно наблюдать тонкую микронодулярную структуру ксерогеля с различимой пространственной упаковкой из полимерных цепочек. Структура образца углеродного ТФ-геля гомогенная и состоит из компактно упакованных однородных гранул размером 5-10 нм.

Таким образом, в результате карбонизации органического геля происходит образование жесткого углеродного каркаса из близких по размеру и упорядоченных пор нанометрового размера. 
Термическая устойчивость органического ТФ(HCl)-ксерогеля была изучена в атмосфере аргона методом термогравиметрии (рис. 7). На кривой ДТГ (кривая 2) присутствует лишь один широкий пик с максимумом при $393,3{ }^{\circ} \mathrm{C}$, он практически совпадает с температурным максимумом при $390,7^{\circ} \mathrm{C}$ на ДСК (кривая 1). Это может свидетельствовать о сходном характере термораспада компонентов геля [31].

Как следует из анализа полученных данных и из профиля убыли массы от температуры ТГ (кривая 3), процесс потери массы ксерогелем можно условно разделить на несколько стадий. В табл. 2 представлены основные характеристики процесса термодеструкции органического ТФ-геля - условные термические интервалы $\left({ }^{\circ} \mathrm{C}\right)$, средние скорости убыли массы в этих интервалах $(\mathrm{V}, \% /$ мин) и потеря веса $(\nabla \mathrm{m}, \%)$.

Начальная стадия убыли массы (около $3 \%$ отн.) в интервале температур до $148{ }^{\circ} \mathrm{C}$ протекает в эндотермической области с низкой скоростью убыли массы ( $-0,26 \% /$ мин) и, вероятно, связана с удалением остаточного растворителя из пористой структуры геля. Значительная потеря массы образцом начинается при температурах выше $295{ }^{\circ} \mathrm{C}$, скорость потери массы возрастает до - $1,67 \%$ мин. Наибольшая убыль массы ( $\approx 31 \%)$ в основном происходит в интервале температур $295-480{ }^{\circ} \mathrm{C}$. Заключительный этап терморазложения при подъеме температуры до $800{ }^{\circ} \mathrm{C}$ характеризуется замедлением скорости убыли массы $(-0,43 \% /$ мин) и завершается образованием углеродного остатка с выходом 45,15\%.

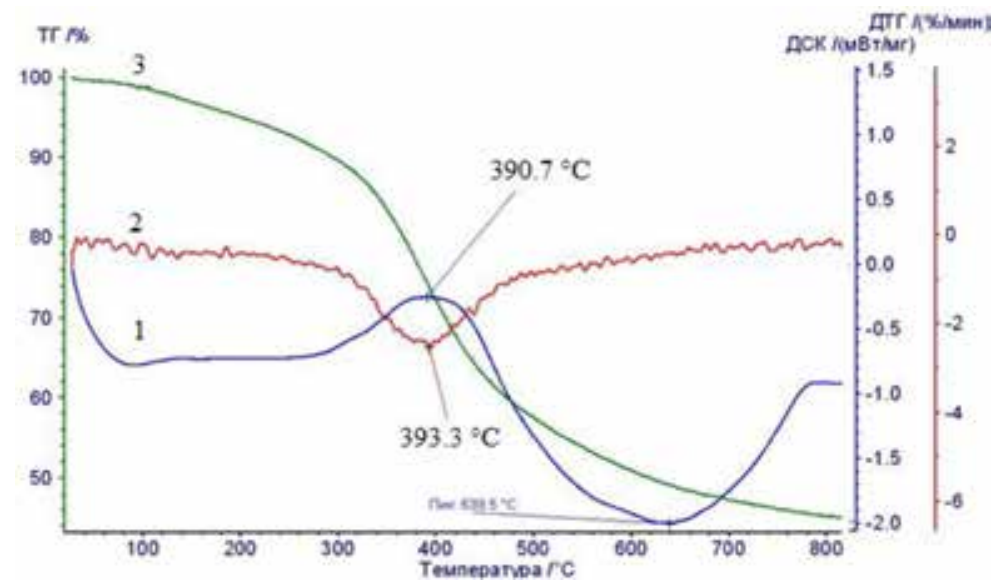

Рис. 7. Термограмма образца органического ТФ( $\mathrm{HCl})$-ксерогеля

Fig. 7. Thermogram of a sample of organic $\mathrm{TF}(\mathrm{HCl})$ xerogel

Таблица 2. Основные этапы термодеструкции органического ТФ(НCl)-ксерогеля, полученного из танинов коры пихты

Table 2. The main stages of thermal decomposition of organic $\mathrm{TF}(\mathrm{HCl})$ xerogel obtained from abies bark tannins

\begin{tabular}{|c|c|c|c|c|c|}
\hline Интервал, ${ }^{\circ} \mathrm{C}$ & $\leq 148$ & $148-295$ & $295-480$ & $480-800$ & \multirow{2}{*}{ Остаток } \\
\hline$\nabla \mathrm{m}, \%$ & 3,0 & 7,0 & 30,9 & 13,95 & \multirow{2}{*}{45,15} \\
\cline { 1 - 5 } $\mathrm{V}, \% /$ мин & $-0,26$ & $-0,47$ & $-1,67$ & $-0,43$ & \\
\hline
\end{tabular}


На ДСК-кривой этому высокотемпературному периоду отвечает интенсивный эндоэффект с широким пиком при $640{ }^{\circ} \mathrm{C}$, что, вероятно, указывает на формирование карбонизованного продукта.

Относительно высокая термическая стабильность органического ТФ-ксерогеля сочетается с его устойчивостью к воспламенению при повышенных температурах. Экспериментально установлено, что полученные органические ТФ-ксерогели не горят в присутствии воздуха даже при высокой температуре $\left(600^{\circ} \mathrm{C}\right)$, а постепенно трансформируются в углеродистый материал. Благодаря таким термическим свойствам эти гели имеют перспективы применения в качестве огнезащитных материалов.

\section{Заключение}

Предложен способ синтеза органических гелей (ксерогелей), основанный на конденсации танинов коры пихты с формальдегидом и последующей сушке при нормальных условиях.

На основании данных, полученных методами ИКС, СЭМ, элементного анализа и БЭТ, установлено, что строение и параметры пористой структуры органических танин-формальдегидных ксерогелей аналогичны аэрогелям, синтезированным на основе танинов квербахо, выделяемых из коры тропических растений.

Методом термогравиметрии определено, что органические ксерогели на основе танинов пихты термически стабильны вплоть до температуры $295^{\circ} \mathrm{C}$ и проявляют устойчивость к воспламенению на воздухе при температурах до $600{ }^{\circ} \mathrm{C}$. Благодаря этим свойствам они могут найти применение в качестве термо- и огнезащитных материалов.

Карбонизацией органических ксерогелей из танинов пихты получены углеродные ксерогели с величиной удельной поверхности 483-524 м²/г. Методом СЭМ показано, что при карбонизации органических ксерогелей сохраняется трехмерно сшитая структура из полимерных цепочек, сформированных однородными частицами глобулярной формы размером 5-10 нм, образующих поры нанометрового размера $(\leq 1,5$ нм).

Таким образом, использование нового возобновляемого и доступного источника полифенольных соединений - танинов коры пихты расширяет возможности для приготовления органических и углеродных ксерогелей с однородной структурой пор, перспективных для применения в качестве термоизоляторов, адсорбентов, носителей катализаторов и в других областях.

\section{Благодарности / Acknowledgements}

Работа выполнена в рамках государственного задания Института химии и химической технологии СО РАН (Проект V.46.4.2; № 0356-2019-0032). В работе использовано оборудование Красноярского регионального центра коллективного пользования ФИЦ КНЦ СО РАН.

This work was performed at the Institute of Chemistry and Chemical Technology, Siberian Branch, Russian Academy of Sciences within the framework of a state contract (Project V.46.4.2; No. 0356-2019-0032). The work used the equipment of the Krasnoyarsk Regional Center for Collective Use of the FIC KSC of the SB RAS. 


\section{Список литературы / References}

1. Du A., Zhou B., Zhang Z.H., Shen J. A special material or a new state of matter: A review and reconsideration of the aerogel. Materials. 2013. Vol. 6, P. 941-968.

2. Pierre A.C., Pajonk G.M. Chemistry of aerogels and their applications. Chem. Rev. 2002. Vol. 102, P. 4243-4265.

3. Chen H.B., Hollinger E., Wang Y.Z., Schiraldi D.A. Facile fabrication of poly (vinyl alcohol) gels and derivative aerogels. Polymer. 2014. Vol. 55, P. 380-384.

4. Moreno-Castilla C., Maldonado-Hodar F.J. Carbon aerogels for catalysis applications: an overview. Carbon. 2005. Vol. 43(3), P. 455-465.

5. Celzard A., Fierro V., Amaral-Labat G. Adsorption by carbon gels. In: Tascon JMD, ed. Novel carbon adsorbents. Oxford: Elsevier; 2012, P. 207-244.

6. Amaral-Labat G., Szczurek A., Fierro V., Stein N., Boulange C., Pizzi A., Celzard A. Pore structure and electrochemical performances of tannin-based carbon cryogels. Biomass Bioenergy. 2012. Vol. 39, P. 274-282.

7. Rey-Raap N., Arenillas A., Menendez J.A. Carbon gels and their applications: a review of patents, in Submicron Porous Materials, ed. by P. Benotti (Springer, New York, 2017), P. 25-52.

8. Li J., Wang X., Huang Q., Gamboa S., Sebastian P.J. Studies on preparation and performances of carbon aerogel electrodes for the application of supercapacitor. J Power Source. 2006. Vol. 158(1), P. 784-788.

9. Koebel M.,Rigacci A.,Achard P. Aerogel-based thermal superinsulation: An overview. J. SolGel Sci. Technol. 2012. Vol. 63, P. 315-339.

10. Rey-Raap N., Calvo E.G., Menendez J.A., Arenillas A. Exploring the potential of resorcinol-formaldehyde xerogels as thermal insulators. Micropor Mesopor Materials. 2017. Vol. 244, P. 50-54.

11. Scherdel C., Reichenauer G. Carbon xerogels synthesized via phenol-formaldehyde gels. Micropor. Mesopor. Materials. 2009. Vol. 126, P. 133-142.

12. Al-Muhtaseb S.A., Ritter J.A. Preparation and properties of resorcinol-formaldehyde organic and carbon gels. Adv. Mater. 2003. Vol. 15, P. 101-114.

13. Wu D.C., Fu R.W., Sun Z.Q., Yu Z.Q. Low-density organic and carbon aerogels from the solgel polymerization of phenol with formaldehyde. J. Non-Cryst. Solids. 2005. Vol. 351, P. 915-921.

14. Job N., Thery A., Pirard R., Marien J., Kocon L., Rouzaud J.N., Beguin F., Pirard J-P. Carbon aerogels, cryogels and xerogels: influence of the drying method on the textural properties of porous carbon materials. Carbon. 2005. Vol. 43(12), P. 2481-2494.

15. Duval A., Averous L. Characterization and physico-chemical properties of condensed tannins from Acacia catechu. J. Agricult. Food Chem. 2016. Vol. 64(8), P. 1751-1760.

16. Amaral-Labat G., Grishechko L.I., Fierro V., Kuznetsov B.N., Pizzi A., Celzard A. Tanninbased xerogels with distinctive porous structures. Biomass and Bioenergy. 2013. Vol. 56, P. 437-445.

17. Szczurek A., Amaral-Labat G., Fierro V., Pizzi A., Masson E., Celzard A. The use of tannin to prepare carbon gels. Part I. Carbon aerogels. Carbon. 2011. Vol. 49, P. 2773-2784.

18. Scioneaux A.N., Schmidt M.A., Moore M.A., Lindroth R.L., Wooley S.C., Hagerman A.E. Qualitative Variation in Proanthocyanidin Composition of Populus Species and Hybrids: Genetics is the Key. J Chem Ecol. 2011. Vol. 37, P. 7-70. 
19. Diouf P.N., Tibirna C.M., Garcia-Perez M-E., Rouer M., Dube P., Stevanovic T. Structural elucidation of condensed tannin from Piceamariana bark. Journal of Biomaterials and Nanobiotechnology. 2013. Vol. 4, P. 1-8.

20. Tondi G., Fierro V., Pizzi A., Celzard A. Tannin-based carbon foams. Carbon. 2009. Vol. 47, P. 1480-1492.

21. Mikova N.M., Grishechko L.I., Skvortsova G.P. and Kuznetsov B.N. Polyphenols of Wood Bark: Organic Precursors for the Production of Polymer Aerogels. Russ. J. Bioorganic Chem. 2018. Vol. 44(7), P. 845-853.

22. Szczurek A., Amaral-Labat G., Fierro V., Pizzi A., Celzard A. The use of tannin for preparing carbon gels. Part II. Carbon cryogels. Carbon. 2011. Vol. 49(8), P. 2785-2794.

23. Moreno A.H., Arenillas A., Calvo E.G., Bermudez J.M., Menendez J.A. Carbonization of resorcinol-formaldehyde organic xerogels: effect of temperature, particle size and heating rate on the porosity of carbon xerogels. J. Anal. Appl. Pyrolysis. 2013. Vol. 100, P. 111-116.

24. Zulamita Zapata-Benabithe, Giovanna Diossa, Chris. D. Castro, Germán Quintana. Activated Carbon Bio-Xerogels as Electrodes for Super Capacitors Applications. Proceed. Enginer. 2016. Vol. 148, P. $18-24$.

25. Grishechko L.I., Amaral-Labat G., Fierro V., Szczurek A., Kuznetsov B.N., Celzard A. Biosourced, highly porous, carbon xerogel microspheres. RSC Adv. 2016. Vol. 6, P. 65698 -65708.

26. Pekala R.W. Organic aerogels from the polycondensation of resorcinol with formaldehyde. J. Mater. Sci. 1989. Vol. 24, P. 3221-3227.

27. Gallegos-Suarez E., Perez-Cadenas A.F., Maldonado-HodarJ.F., Carrasco-Marin F. On the micro- and mesoporosity of carbon aerogels and xerogels. The role of the drying conditions during the synthesis processes. Chemical Engineering Journal. 2012. Vol. 181-182, P. 851-855.

28. Rey-Raap N., Szczurek A., Fierro V., Menendez J.A., Arenillas A., Celzard A. Towards a feasible and scalable production of bio-xerogels. J. Colloid and interface Science. 2015. Vol. 456, P. 138-144.

29. Gregg S.J., Sing K.S.W. Adsorption, Surface Area and Porosity. New York: Academic Press, 1991. $303 \mathrm{p}$.

30. Zhao S., Malfait W.J., Guerrero-Alburquerque N., Koebel M.M., Nystrom G. Biopolymer Aerogels and Foams: Chemistry, Properties, and Applications. Angew. Chem. Int. Ed. 2018. Vol. 57, P. $7580-7608$.

31. Arenillas A., Menendez J.A., Reichenauer G., Celzard A., Fierro V., Maldonado-Hodar J.F., Bailón-Garcia E., Job N. Organic and Carbon Gels. From Laboratory Synthesis to Applications, in Advances in Sol-Gel Derived Materials and Technologies, ed. by Aegerter M.A. and Prassas M. (Springer, Switzerland, 2019), pp. 27-191.

32. Zuo L., Zhang Y., Zhang L., Miao Y-E, Fan W., Liu T. Polymer/Carbon-Based Hybrid Aerogels: Preparation, Properties and Applications. Materials. 2015. Vol. 8, P. 6806-6848.

33. Rey-Raap N., Szczurek A., Fierro V., Celzard A., Menendez J.A., Arenillas A. Advances in tailoring the porosity of tannin-based carbon xerogels. Ind. Crop. Prod. 2016. Vol. 82, P. 100-106.

34. IUPAC Manual of Symbols and Terminology Appendix 2, Part. 1 IUPAC. Pure and Applied Chemistry. 1972. Vol. 31(4), P. 579-638.

35. Amaral-Labat G., Szczurek A., Fierro V., Pizzi A., Celzard A. Systematic studies of tanninformaldehyde aerogels: preparation and properties. Sci Technol Adv Mater. 2013. Vol. 14(1), P. 015001. 